\title{
Review
}

\section{Future possibilities in the prevention of breast cancer Intervention strategies in BRCA1 and BRCA2 mutation carriers} Rosalind A Eeles

\author{
Institute of Cancer Research and Royal Marsden NHS Trust, Sutton, Surrey, UK
}

\begin{abstract}
The development of intervention strategies for carriers of mutations in the BRCA1 and $B R C A 2$ genes has several considerations. The first are primary prevention and secondary prevention in unaffected carriers using medical/surgical or lifestyle strategies to prevent cancer development, or screening methods to detect cancers at an earlier stage. The options available are determined by the magnitude and age at onset, risk profile of cancer in carriers (the penetrance function of the gene) and the different cancer sites involved. The management of affected individuals who are BRCA1 and BRCA2 mutation carriers may be altered by their carrier status, because the tumour histology, efficacy of treatment and risk of subsequent cancer development is determined by the BRCA1 and BRCA2 germline status. Carriers of $B R C A 1$ and $B R C A 2$ mutations are relatively rare, so the strategies for management should be determined by international multicentre studies.
\end{abstract}

Keywords: $B R C A 1, B R C A 2$, interventions, management, mutation carriers

\section{Introduction}

About $5-10 \%$ of breast and ovarian cancers occur as a result of highly penetrant germline mutations in cancer predisposing genes [1,2]. Half of these are due to mutations in BRCA1 or BRCA2 [3]. BRCA1 on chromosome $17 q$ encodes a protein of 1863 amino acids [4 $4^{\circ}$ and $B R C A 2$ on $13 q$ is about twice the size of BRCA1 [5०]. Although deleterious mutations in both genes predispose to earlier onset and an increased risk for female breast cancer, the risk of cancers at other sites and the risk profile differs for the two genes.

BRCA1 and BRCA2 genes and cancer risks Collaborative studies by the Breast Cancer Linkage Consortium (BCLC) have combined data from numerous families with germline mutations in BRCA1 and BRCA2 worldwide to determine penetrance estimates and risks for other cancers in BRCA1 and BRCA2 mutation carriers. These have shown that both genes confer an increased risk for female breast cancer of $80-85 \%$ by the age of 80 years $\left[6,7^{\bullet \bullet}\right]$, although the penetrance curve for $B R C A 1$ starts to rise slightly earlier than that for BRCA2 (Figs 1 and 2). Both genes confer an increased risk for ovarian cancer, but the lifetime risks are higher for $B R C A 1$ (60\% by age 80 years) than for BRCA2 (27\% by age 80 years; the population risk is just under $1 \%$ ), and the penetrance curve also starts to rise earlier (late 30s) for BRCA1 than for BRCA2 (mid 40s; Figs 1 and 2) [7].

It is now clear that both genes confer an increased risk for prostate cancer, which is threefold for BRCA1 mutations [8 ${ }^{\circ}$ and threefold to sevenfold for BRCA2 mutations

$\mathrm{BCLC}=$ Breast Cancer Linkage Consortium; OCP $=$ oral contraceptive pill. 
$\left[9,10^{\circ}\right]$, equating to an absolute risk of $6-14 \%$ by age 74 years; the population risk by this age is $2 \%$. Mutations in $B R C A 1$ are also thought to increase the risk of colon cancer to about $6 \%$ by age 70 years [ $\left.8^{\circ}\right]$, but carriers of mutations in BRCA2 do not appear to be predisposed to colon cancer.

A recent analysis of the risk of other cancers in BRCA2 carriers [10*0 reported a significantly increased risk for cancer of the prostate, stomach, pancreas, male breast, head and neck, ocular melanoma, cutaneous melanoma and fallopian tube, and cancer of the gallbladder and bile duct. Because many of these latter cancers are rare in the general population, the absolute risk is still low in BRCA2 carriers, and targeted screening at these sites, with the exception of prostate cancer, is not warranted.

The ethnic origin of the $B R C A 1$ or $B R C A 2$ carrier is important in refining these penetrance estimates. Studies in Ashkenazi Jews and the Icelandic population have reported lower lifetime penetrance estimates for breast cancer of $50-60 \%$ in the Ashkenazim [11] and 37\% in the Icelandic population [12]. The risks of ovarian cancer are also lower in the Ashkenazim [11] than in the overall BCLC estimates.

Some researchers have reported a genotype-phenotype correlation of mutation position and breast/ovarian cancer risk [13], with mutations at the $5^{\prime}$ end of $B R C A 1$ and the central part of $B R C A 2$ conferring a higher risk for ovarian cancer. What is unclear is whether this represents a higher risk for ovarian cancer per se or a relatively lower risk for breast cancer, and further studies within the BCLC dataset are ongoing.

Table 1 summarizes the risks for cancers in $B R C A 1$ and BRCA2 mutation carriers [14].

\section{Detection of BRCA1 and BRCA2 carriers}

Over 200 distinct mutations in BRCA1 and BRCA2 have been described, and are listed in a database on the Internet [15-17]. These mutations are widely scattered across both genes. Most mutations truncate the protein product, but a significant proportion (34\% of BRCA1 and $38 \%$ of $B R C A 2$ mutations [17]) are missense mutations that alter one amino acid, but do not truncate the protein and are of uncertain significance (so-called variants of uncertain significance). At present, the cancer risks from such variants are uncertain and most cancer geneticists would not offer predictive genetic testing for such variants. It is likely that some, but not all will transpire to be rare polymorphisms (normal variants).

Because many different mutations have been described in different families (apart from founder mutations in certain populations such as the Ashkenazim and Icelanders
Figure 1

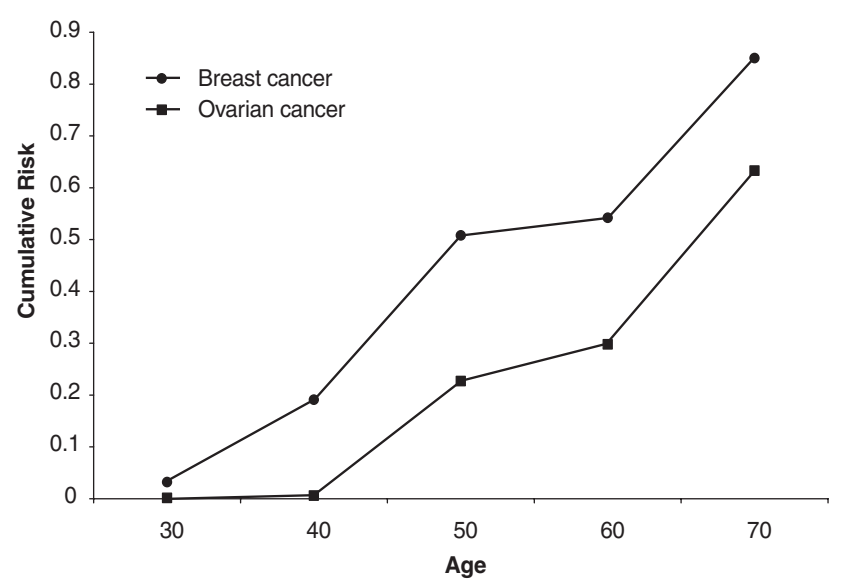

$B R C A 1$ breast/ovarian cancer risk.

Figure 2

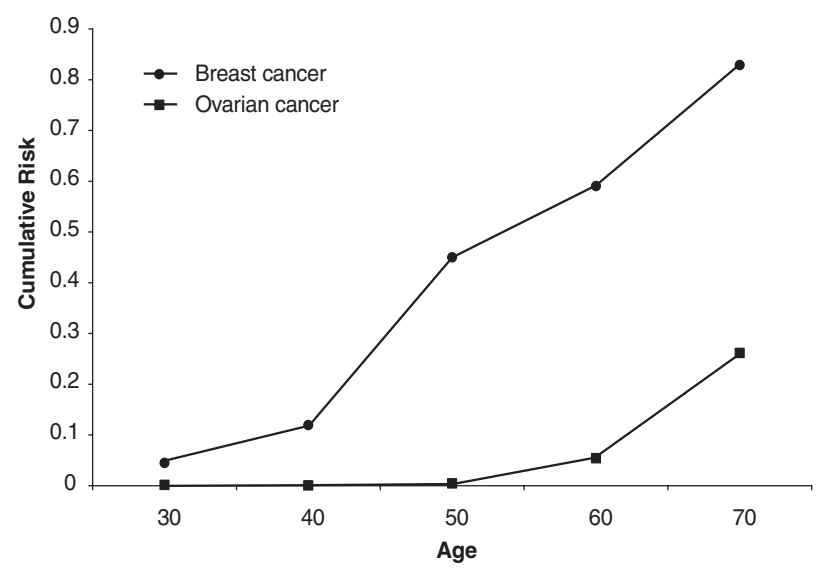

$B R C A 2$ breast/ovarian cancer risk.

$\left.\left[18-21,22^{\circ}, 23\right]\right)$, when an individual wishes to know their $B R C A 1$ and $B R C A 2$ carrier status, the mutation present in the familial cancer cluster is first determined by mutation screening of blood DNA from an affected family member (diagnostic testing) and a predictive genetic test is then offered to the unaffected family member who is seeking testing when the mutation is identified. The predictive test only ascertains whether the unaffected relative has that specific mutation. It is recommended that predictive genetic testing is preceded by full counselling of at least two sessions, interspersed with a minimum 1-month 'cooling off' period, similar to the genetic testing protocol for Huntington's disease [24]. At present, the optimal method of counselling for both affected and unaffected members of the family is unknown; affected members who give a blood sample to determine the mutation often 
Table 1

Lifetime (by age 80 years) cancer risks (\%) in BRCA1/BRCA2 mutation carriers

\begin{tabular}{|c|c|c|c|c|c|}
\hline \multirow[b]{2}{*}{ Gene } & \multicolumn{5}{|c|}{ Cancer type } \\
\hline & Female breast & Ovarian & Male breast & Colon & Prostate $^{\star}$ \\
\hline$B R C A 1$ & $80-85$ & 60 & ?0 & 6 & 6 \\
\hline BRCA2 & $80-85$ & 27 & 5 & ?० & $6-14$ \\
\hline
\end{tabular}

*By age 74 years. Data from [14].

Table 2

\begin{tabular}{|c|c|}
\hline $\begin{array}{l}\text { Chance that } \\
\text { a mutation is } \\
\text { present* }^{\star}\end{array}$ & Clinical criteria \\
\hline$<10 \%$ & All single cases of breast or ovarian cancer \\
\hline $10 \%$ & Single breast cancer cases aged $<35$ years \\
\hline$>10-\leq 30 \%$ & $\begin{array}{l}\text { Two breast cancer cases aged }<50 \text { years } \\
\text { One breast cancer case aged }<40 \text { years in an } \\
\text { Ashkenazi jew }\end{array}$ \\
\hline$\leq 50 \%$ & $\begin{array}{l}\text { Three breast cancer cases aged }<50 \text { years } \\
\text { Four to five breast cancer cases, no ovarian cancer } \\
\text { One breast and ovarian cancer case }\end{array}$ \\
\hline$>50 \%$ & $\begin{array}{l}\text { More than one breast and ovarian cancer case } \\
\text { At least four cases of female/male breast cancer } \\
\text { More than six female breast cancer cases }\end{array}$ \\
\hline
\end{tabular}

*The chance of detecting a mutation is lower, because at least $15 \%$ of mutations are regulatory (ie they are not in the coding region of the gene that is the area tested), and the genetic screening methods are approximately $80 \%$ sensitive if sequencing is not used. Cases refer to first-degree relatives or first/second-degree relatives if multiple cases. Data from $\left[7^{\bullet}, 16,19,21,23,25,72\right]$.

receive less counselling than the unaffected individual. One may postulate that they may need more support, because they have a cancer diagnosis that they then learn has a genetic basis and this may have been passed on to future generations. The counselling requirements of affected persons need to be studied. The chance of a mutation being present in BRCA1 or BRCA2 in certain clusters is shown in Table 2.

\section{Management of unaffected BRCA1 and BRCA2 mutation carriers}

There are currently several approaches to the management of men and women who are carriers of BRCA1 and BRCA2 mutations. The options available depend on whether the individual is already affected or is unaffected with cancer. Broadly, for an unaffected carrier, these options are as follows: early detection through screening programmes; changes in lifestyle; chemoprevention; and prophylactic surgery.

\section{Early detection through screening}

Breast screening

The value of mammographic screening for female carriers of $B R C A 1$ and BRCA2 mutations is currently under evaluation. Population mammographic screening is offered in the UK to those aged from 50 to 65 years every 3 years, because this has been shown to reduce mortality by at least 20\% (for summary [26]). However, BRCA1 and $B R C A 2$ carriers are at risk for early-onset breast cancer, and just over half of this risk occurs at ages before the start of the screening programme. Guidelines for individuals who have a family history of breast cancer (not specifically BRCA1 and BRCA2 mutation carriers) have just been compiled by the UK Cancer Family Study Group [27]. Lalloo et al [28] have shown that mammographic screening of a population aged under 50 years with a family history (the genetic status was not determined) detects as many cancers per 1000 women screened as the UK National Breast Screening Programme. The cancers detected were not all indolent preinvasive tumours. However, no study has yet proven that targeted screening of younger women with a family history of breast cancer improves survival.

It is common practice to offer annual mammography from ages 35-50 years in BRCA1 and BRCA2 carriers, but the screening interval after 50 years is undefined. The penetrance curves for breast cancer risk continue to rise until ages 75-80 years, and so many clinics offer annual mammography until the mid-70s. The screening interval in women with a family history only (not BRCA1 and $B R C A 2$ carriers) is extended to 18 months after age 50 years. This is because, in the general population, invasive interval cancers are more frequent among women aged 40-49 years than in older women, but this is not due to a difference in the S-phase fraction in tumours in older women [29].

If there is a very young individual ( $<30$ years) with breast cancer in the family, many units will start mammographic screening at 30 years, but there is concern about radiation-induced tumours if mammography is instigated any younger than this. This is based on extrapolations from atomic bomb radiation exposure data [30]. Furthermore, it 
is now thought that BRCA1 and BRCA2 may mend double-strand breaks, and they colocalize with rad51 [31 $\left.{ }^{\circ}\right]$. We have preliminary data from normal fibroblast clonogenic radiation survival curves and DNA repair assays that $B R C A 1$ carriers are not more radiosensitive and are not DNA repair deficient when compared with related noncarriers from the same family [32] (unpublished data), but those studies were based on doses equivalent to those used in therapy rather than screening, and the numbers are very small (six carriers). There are no human radiosensitivity data for BRCA2 heterozygous normal cells.

The teaching of breast awareness is practiced in many breast clinics that manage $B R C A 1$ and $B R C A 2$ mutation carriers, and studies in the general population [33] have shown that it downstages nodal status in tumours at presentation, but it does not appear to reduce mortality.

Alternative methods of breast imaging are being assessed in BRCA1 and BRCA2 mutation carriers and in women of unknown mutation status in high-risk families using magnetic resonance imaging of the breast with gadolinium contrast enhancement [34]. Breast magnetic resonance imaging has some potential advantages because it does not use irradiation and is more sensitive than mammography. There is also concern that $B R C A 1$-associated breast cancers have a lower proportion of ductal carcinoma in situ than those in BRCA2 carriers [35'], and therefore they may be less easily detected on mammography.

\section{Ovarian screening}

This is more controversial because ovarian screening in highrisk women has not yet been shown to reduce mortality, although a population-based study [36] showed a mortality reduction $(P=0.0112)$. There is an ongoing United Kingdom Coordinating Committee for Cancer Research trial of ovarian screening with annual transvaginal ultrasound and CA125 measurement in women with at least two cases of ovarian cancer or breast and ovarian cancer in their family history. $B R C A 1$ and $B R C A 2$ carriers can be entered into this study. Screening is started at age 30 years for $B R C A 1$ and at 35 years for $B R C A 2$ mutation carriers because of the later start of rise in level of ovarian cancer risk for BRCA2.

\section{Prostate screening}

Targeted prostate cancer screening in first-degree relatives of brother pairs with the disease has demonstrated a higher detection rate of prostate cancer than expected [37], but whether there is a reduction in mortality is uncertain. A study of prostate-specific antigen and digital rectal examination screening in male carriers of BRCA1 and $B R C A 2$ is being proposed (Eeles et al, unpublished data).

Other cancers

From Table 1, there is also a risk for colon cancer in BRCA1 carriers, but in families with multiple cases of colon cancer colonoscopic screening is only offered if the lifetime risk is greater than $10 \%$. Furthermore, there is an increased incidence of right-sided colonic tumours in hereditary nonpolyposis colorectal cancer families [38]. In $B R C A 1$ carriers, the lifetime risk is $6 \%$, and it is unknown whether there is a side predilection for these tumours. If studies confirm the increased risk for colon cancer and show it to be left sided, sigmoidoscopy screening may suffice. This is a question that needs to be answered. The risk for male breast cancer in BRCA2 carriers is small (5\% lifetime), but is still 100 -fold that in the general population. Mammography is not feasible and may not be warranted anyway at this level of risk, and self-examination is suggested. Male breast cancer in $B R C A 2$ carriers is very rare in those aged less than 50 years.

Carriers of mutations in the BRCA2 gene are also at risk for other cancers. The absolute lifetime risks are very low, but one cancer that can be monitored by the carrier is cutaneous melanoma. There should be a low threshold for examination of any suspicious skin lesions by a dermatologist.

\section{Changes in lifestyle}

A number of lifestyle factors have been shown to influence the development of breast cancer in the general population, although most of these have not been specifically investigated in BRCA1 and BRCA2 mutation carriers. The factors that have been shown to affect female breast cancer risk in the general population but that have not been investigated in BRCA1 and BRCA2 carriers are diet, alcohol intake, exercise and hormone replacement therapy. Smoking has been shown to reduce breast cancer in $B R C A 1$ and BRCA2 carriers, probably due to an antioestrogenic effect [39], but its carcinogenic properties at other sites precludes its use to reduce breast cancer risk. The oral contraceptive pill (OCP) reduces the risk for ovarian cancer in BRCA1 and BRCA2 carriers to the same degree as in the general population, but its effect on breast cancer risk has not yet been reported. Modelling of breast and ovarian cancer mortality without any surgical intervention is difficult to achieve because it is unknown whether the risk of breast cancer in BRCA1 and BRCA2 carriers who take the OCP is the same as that in the general population. If a prophylactic oophorectomy is performed, however, this has been shown $\left[40^{\circ}, 41^{\circ}\right]$ to reduce both breast and ovarian cancer risk, and if use of the OCP raised breast cancer risk it could theoretically be disadvantageous to take the OCP because the reduction in ovarian cancer risk could be provided by the surgical option. Early age at first pregnancy does not seem to offer protection from breast cancer, unlike in sporadic disease [42].

\section{Chemoprevention}

The role of tamoxifen prevention is discussed at length in another review in the present issue [43]. In brief, tamoxifen may reduce the incidence of breast cancer in the white 
American population by $45 \%$ [44." $]$, but two further publications $\left[45^{\circ}, 46^{\circ}\right]$ have failed to show this effect. It is possible that the studies used different populations of women with different familial cancer risks, which may have affected the outcomes of the trials. Theoretically, chemoprevention with tamoxifen may be less effective in BRCA1 carriers, because their tumours are more likely to be oestrogen receptor negative [35].

\section{Prophylactic surgery}

Prophylactic mastectomy to reduce breast cancer risk is increasingly being offered to carriers of $B R C A 1$ and BRCA2 mutations. The uptake of this option is lower in the USA [47] than in the UK [48] and Holland [49]. Its efficacy is unproven, but retrospective data [50*] have suggested that there is a $90 \%$ reduction in mortality. Prophylactic oophorectomy reduces mortality from ovarian cancer [40 ${ }^{\circ}$, and also from breast cancer in BRCA1 and BRCA2 carriers $\left[41^{\circ}\right]$. There has been a reported case of a male having prophylactic mastectomy [51]; he was at a one in two risk in a BRCA2-like family in which no mutation could be found. His lifetime breast cancer risk was, in fact, only $2.5 \%$, which is lower than the general population female breast cancer risk. This highlights the issue that levels of anxiety weigh heavily in the decision-making process to proceed with prophylactic surgery, and may be more influential than the absolute level of risk [52]. Because of the body-image issues surrounding prophylactic mastectomy, it is recommended that individuals who are considering prophylactic mastectomy should be offered a protocol of a cancer genetics risk assessment, a clinical psychological assessment, and consultations with the breast surgeon and clinical nurse specialist in breast care. This should include being shown photographs of good and poor cosmetic results, and the breast surgeon should either have extensive experience in reconstructive surgery or work closely with a plastic surgeon.

The type of mastectomy offered will depend on the woman's physique and preference. For prophylaxis, as much as possible of the breast tissue is removed, and either an implant is inserted or a tram flap is used (the muscle of the flap replacing the breast tissue). There is no evidence that silicone implants are associated with an increased cancer risk [53]. Prospective studies of the efficacy of these operations are needed.

Prophylactic oophorectomy reduces the risk of ovarian cancer [40], but cancer can still occur in the peritoneum because these cells have the same embryological origin as those on the surface of the ovary. The chance of this occurring is uncertain, but may be as low as $2-3 \%$ [54].

\section{Management of affected BRCA1 and BRCA2 mutation carriers}

The following issues have to be considered in the management of a BRCA1 and BRCA2 mutation carrier who is affected with cancer: is the tumour pathology any different and does this impact upon management of the tumour?; is the survival from the cancer any different?; issues surrounding radiosensitivity or chemosensitivity; screening for second primary cancers; and prophylactic surgery.

\section{Tumour pathology, and impact on management and survival}

Breast cancer in BRCA1 mutation carriers tends to be of higher grade and to have a higher proportion of atypical medullary cancer and a lower proportion of carcinoma in situ [55]. BRCA2 has a lower rate of tubule formation, which is a bad prognostic feature [35']. Mutiple regression of the pathological features of the breast cancers in $B R C A 1$ and BRCA2 mutation carriers shows that the main pathological predictor of $B R C A 1$ is mitotic count, lymphocytic infiltration and continuous pushing margins, but not the medullary phenotype per se. This would predict that the survival from breast cancer in $B R C A 1$ carriers would be worse, but studies of survival from breast cancer in BRCA1 carriers show conflicting results. Thirtyone studies related to survival from breast cancer and familial factors were reported between 1996 and 1999; these were summarized in a review by Chappuis et al [56"*]. These were divided into family history studies, linkage studies and mutation-based studies. Of the family history studies (18 studies in total), four showed a better survival in individuals with a family history than in those without, two showed worse survival and the rest showed no difference. In the linkage studies (three studies in total), two families linked to BRCA1 had a better survival and one linked to BRCA2 had a worse survival relative to the general population. Finally, in the mutation-based studies (10 studies in total), eight showed no difference and two showed a worse outcome in mutation carriers relative to those in the general population.

No study conclusively proves that survival is improved in $B R C A 1$ carriers. The problem with these studies is that there is inherent bias because most mutation detection has to be performed on DNA from blood, and the woman with breast cancer therefore have to be alive to be tested. This can partly be overcome in two ways; the first is to ignore the proband that was tested in the survival analysis. When this was done in the study by Verhoog et al [57], the survival changed from no difference to a worse survival in BRCA1 carriers, although this was not statistically significantly different. The second method is to take stored breast cancer tumour material from all patients and test for $B R C A 1 / B R C A 2$ mutations. This is currently only feasible in a population such as the Jewish population in which the entire gene does not have to be screened for mutations, because they have three common founder mutations in BRCA1/BRCA2; such studies by Foulkes et al [58] and Lee et al [59] in Jewish women showed no difference in survival. Only the studies in Jewish women and another 
study by Verhoog et al [60] have studied survival in women with breast cancer due to BRCA2 mutations. These suggest that the survival from breast cancer in $B R C A 2$ carriers is the same as in the general population. Such tumours tend to be oestrogen receptor positive; this feature is a good prognostic factor in sporadic patients.

If BRCA1-associated breast cancer has a worse prognosis, it may be important to offer radical therapy even to those with very early tumours. For example, this may be a group in which even very small $(<1 \mathrm{~cm})$ grade 3 tumours should be treated with adjuvant chemotherapy, an area in which at present there is controversy about the role of adjuvant chemotherapy [61].

Robson et al [62] have shown that women with founder $B R C A 1 / B R C A 2$ Jewish mutations are at increased risk for ipsilateral breast cancer-related events after breast conservation, although this was not statistically significant. There is a statistically significant increased contralateral breast cancer risk (relative risk 3.50, 95\% confidence interval 1.78-8.74; $P=0.001$ ). Oncologists are considering the appropriateness of conservative management in view of such results. As yet, the data are not strong enough to prove bilateral mastectomy as the management of choice, but studies of follow up of carriers such as those being conducted by Easton, Goldgar and Narod, within the BCLC, will help to answer this question.

There are data that suggest that survival is worse in ovarian cancer that occurs in familial cases with or without an association with BRCA1/BRCA2 mutations [63-67].

\section{Issues surrounding radiosensitivity or chemosensitivity}

It is not yet known whether tumours in BRCA1 or BRCA2 mutation carriers have a different sensitivity to DNA damaging agents. Mice that are brca1 or brca2 null have increased radiosensitivity and chemosensitivity [68-70], but human BRCA1 heterozygote fibroblasts do not seem, on preliminary data, to have an increased radiosensitivity [32]. It should, however, be emphasized that the human data are based on very small numbers and are for high dose rate irradiation of fibroblasts only. This does not provide data on BRCA2 or low dose rate irradiation.

\section{Screening for second primary cancers and prophylactic surgery}

After cancer development in a BRCA1 or BRCA2 mutation carrier, they are at risk for second primary cancers. The risk for development of a second primary breast cancer after the first breast cancer in women is 64\% and $56 \%$ lifetime in BRCA1 and BRCA2 mutation carriers, respectively $\left[7^{\circ \cdot}\right]$; the balance of risk of cancer recurrence from the first primary and risk of a second cancer therefore needs to be considered in the management of the individual carrier with cancer. Prophylactic surgery for the risk of certain second cancers can also be used to help with treatment of the first primary cancer; it has been shown that oophorectomy improves survival from breast cancer in large meta-analyses [71]. Such surgery can therefore be used as part of the treatment of the first cancer to improve survival, and reduce risk of a subsequent new cancer.

\section{Conclusion}

The cancer risk profile of $B R C A 1$ and $B R C A 2$ mutation carriers is becoming clearer, although uncertainties still exist regarding the differences between ethnic groups, the extent of genotype-phenotype interactions, the influence of environment on phenotypic expression and the effect of genotype on outcome after cancer treatment. The relative rarity of $B R C A 1$ and $B R C A 2$ carriers means that the study of these questions will necessarily be in large multicentre, international trials. The discovery of other breast cancer predisposing genes that may be more prevalent and of lower penetrance will result in the development of tailored treatment and prevention strategies for oncology patients according to their cancer-predisposing genetic profile.

\section{References}

Articles of particular interest have been highlighted as:

- of special interest

-. of outstanding interest

1. Easton D, Peto J: The contribution of inherited predisposition to cancer incidence. Cancer Surveys 1990, 9:395-416.

2. Claus EB, Risch N, Thompson WD: Genetic analysis of breast cancer in the Cancer and Steroid Hormone study. Am J Hum Genet 1991, 48:232-242.

3. Easton DF, Ford D, Bishop DT, and the Breast Cancer Linkage Consortium: Breast and ovarian cancer incidence in BRCA1 carriers. Am J Hum Genet 1995, 56:265-271.

4. Miki Y, Swensen J, Shattuck-Eidens D, et al: A strong candidate for - the breast and ovarian cancer susceptibility gene, BRCA1. Science 1994, 266:66-71.

This paper describes the cloning of the BRCA1 gene.

5. Wooster R, Bignell G, Lancaster J, et al: Identification of a breast - $\quad$ cancer gene, BRCA2. Nature 1995, 378:789-791.

This paper describes the cloning of the BRCA2 gene.

6. Ford D, Easton DF, Peto J: Estimates of the gene frequency of $B R C A 1$ and its contribution to breast and ovarian cancer incidence. Am J Hum Genet 1995, 57:1457-1462.

7. Ford D, Easton DF, Stratton MR, et al: Genetic heterogeneity and -. penetrance analysis of the BRCA1 and BRCA2 genes in breast cancer families. Am J Hum Genet 1998, 62:676-689.

This paper describes the proportion of high-risk families due to BRCA1 and $B R C A 2$ and their phenotypic characteristics and is used by cancer geneticists when quoting penetrance figures for the high-risk families.

8. Ford D, Easton DF, Bishop DT, Narod SA, Goldgar DE: Risks of - $\quad$ cancer in BRCA1-mutation carriers. Lancet 1994, 343:692-695.

This is the seminal paper outlining the risks of other cancers, apart from breast cancer in BRCA1 carriers.

9. Phelan CM, Lancaster JM, Tonin $\mathrm{P}$, et al: Mutation analysis of the BRCA2 gene in 49 site-specific breast cancer families. Nature Genet 1996, 13:120-122. 
10. Breast Cancer Linkage Consortium: Carrier risks in BRCA2 mutation -. carriers. J Natl Cancer Inst 1999, 91:1310-1316.

This is the seminal paper outlining the risks of other cancers, apart from breast cancer in $B R C A 2$ carriers.

11. Struewing JP, Hartge $P$, Wacholder $S$, et al: The risk of cancer associated with specific mutations of BRCA1 and BRCA2 among Ashkenazi Jews. N Engl J Med 1997, 336:1401-1408.

12. Thorlacius $S$, Struewing JP, Hartge $P$, et al: Population-based study of risk of breast cancer in carriers of BRCA2 mutation. Lancet 1998, 352:1337-1339.

13. Gayther SA, Warren W, Mazoyer S, et al: Germline mutations of the BRCA1 gene in breast/ovarian cancer families: evidence for a genotype/phenotype correlation. Nature Genet 1995, 11:428-433.

14. Eeles R, Kaduri L: $B R C A 1 / 2$ carriers and endocrine risk modifiers. Endocrine-Related Cancer 1999, 6:521-528.

15. Shattuck-Eidens D, McClure M, Simard J, et al: A collaborative survey of 80 mutations in the BRCA1 breast and ovarian cancer susceptibility gene. JAMA 1995, 273:535-541.

16. Shattuck-Eidens $D$, Oliphant $A, M c C l u r e ~ M$, et al: BRCA1 sequence analysis in women at high risk for susceptibility mutations. JAMA 1997, 278:1242-1250.

17. http://www.nchgr.nih.gov/dir/lab_transfer/bic/

18. Struewing JP, Abeliovich $D$, Peretz $T$, et al: The carrier frequency of the BRCA1 185delAG mutation is approximately 1 percent in Ashkenazi Jewish individuals. Nature Genet 1995, 11:198-200.

19. Neuhausen S, Gilewski T, Norton L, et al: Recurrent BRCA2 617delT mutations in Ashkenazi Jewish women affected by breast cancer. Nature Genet 1996, 13:126-128.

20. Oddoux $\mathrm{C}$, Struewing JP, Clayton $\mathrm{CM}$, et al: The carrier frequency of the BRCA2 6174delT mutation among Ashkenazi Jewish individuals is approximately $1 \%$. Nature Genet $1996,14: 188-190$.

21. Offit K, Gilewski T, McGuire P, et al: Germline BRCA1 185delAG mutations in Jewish women with breast cancer. Lancet 1996, 347:1643-1645.

22. Roa BB, Boyd AA, Volcik K, Richards CS: Ashkenazi Jewish popula-

- tion frequencies for common mutations in BRCA1 and BRCA2. Nature Genet 1996, 14:185-187.

This paper gives results for the frequency of $B R C A 1$ and $B R C A 2$ mutations in Ashkenazi families.

23. Tonin $\mathrm{P}$, Weber $\mathrm{B}$, Offit $\mathrm{K}$, et al: A high frequency of $B R C A 1$ and BRCA2 mutations in 222 Ashkenazi Jewish breast cancer families. Nature Med 1996, 2:1179-1183.

24. Craufurd D, Tyler A: Predictive testing for Huntington's disease: protocol of the UK Huntington's Prediction Consortium. J Med Genet 1992, 29:915-918.

25. Langston AA, Malone KE, Thompson JD, Daling JR, Ostrander EA: BRCA1 mutations in a population-based sample of young women with breast cancer. N Engl J Med 1996, 334:137-142.

26. Chamberlain J: Screening for breast cancer in high-risk populations. In: Genetic Predisposition to Cancer. Edited by Eeles R, Ponder B, Easton D, Horwich A. UK: Chapman \& Hall; 1996.

27. Eccles DM, Evans DGR, Mackay J, et al: Guidelines for a genetic risk-based approach to advising women with a family history of breast cancer. J Med Genet 2000, 37:203-209.

28. Lalloo F, Boggis CR, Evans DG, Shenton A, Threlfall AG, Howell A: Screening by mammography, women with a family history of breast cancer. Eur J Cancer 1998, 34:937-940.

29. Klemi PJ, Toikkanen S, Rasanen O, Parvinen I, Joensuu H: Mammographic screening interval and the frequency of interval cancers in a population-based screening. Br J Cancer 1997, 75:762-766.
30. Tokunaga M, Land CE, Tokuoka S, Nishimori I, Soda M, Akiba S: Incidence of female breast cancer among atomic bomb survivors, 1950-1985. Radiat Res 1994, 138:209-223.

31. Kote-Jarai Z, Eeles RA. BRCA1, BRCA2 and their possible function in DNA damage response. Br J Cancer 1999, 81:1099-1102.

This review summarises the evidence that $B R C A 1$ and $B R C A 2$ are involved in the DNA damage response.

32. Peacock J, McMillan T, Eeles R, et al: Radio-sensitivity of patients carrying defects in the BRCA1 gene. Lancet 2000 , in press.

33. Locker AP, Caseldine J, Mitchell AK, Blamey RW, Roebuck EJ, Elston $\mathrm{CW}$ : Results from a seven-year programme of breast self-examination in 89,010 women. Br J Cancer 1989, 60:401-405.

34. MRI Breast Screening Study Advisory Group: National study of magnetic-resonance imaging to screen women at genetic risk of breast cancer. Lancet Interactive, Protocol Reviews, Protocol P7/4 1998: http://www.thelancet.com/newlancet/reg/author//protocol7_4.html.

35. Lakhani S, Sloane JP, Gusterson BA, et al: A detailed analysis of the - morphological features associated with breast cancer in patients harbouring mutations in $B R C A 1$ and $B R C A 2$ predisposition genes. J Natl Cancer Inst 1999, 90:1138-1145.

This paper showed that the pathological features of breast cancers occurring in $B R C A 1$ carriers are different from those in BRCA2 carriers and those without mutations in either of these genes.

36. Jacobs IJ, Skates SJ, MacDonald N, et al: Screening for ovarian cancer: a pilot randomised controlled trial. Lancet 1999, 353:1207-1210.

37. McWhorter WP, Hernandez AO, Meikle AW, et al: A screening study of prostate cancer in high risk families. J Urol 1992, 148:826-828.

38. Lynch HT, Watson P, Lanspa SJ, et al: Natural history of colorectal cancer in hereditary nonpolyposis colorectal cancer (Lynch syndromes I and II). Dis Colon Rectum 1988, 31:439-444.

39. Brunet JS, Ghadirian P, Rebeck TR, et al: Effect of smoking on breast cancer in carriers of mutant BRCA1 or BRCA2 genes. J Natl Cancer Inst 1998, 90:761-765.

40. Struewing JP, Watson P, Easton DF, Ponder BA, Lynch HT, Tucker

- MA: Prophylactic oophorectomy in inherited breast/ovarian cancer families. J Natl Cancer Inst Monogr 1995, 17:33-35.

This reference shows that prophylactic oophorectomy reduces ovarian cancer risk

41. Rebbeck T, Levin AM, Eisen A, et al: Breast cancer risk after bilat-

- eral prophylactic oophorectomy in BRCA1 mutation carriers. $J$ Natl Cancer Inst 1999, 91:1475-1479.

This reference shows that prophylactic oophorectomy reduces both ovarian and breast cancer risk in $B R C A$ carriers.

42. Jernström $\mathrm{H}$, Lerman $\mathrm{C}$, Ghadirian $\mathrm{P}$, et al: Pregnancy and risk of early breast cancer in carriers of BRCA1 and BRCA2. Lancet 1999, $354: 1846-1850$.

43. Cuzick J: Future possibilities in the prevention of breast cancer: breast cancer prevention trials. Breast Cancer Res 2000, 2:258-263.

44. Fisher B, Costantino JP, Wickerham DL, et al: Tamoxifen for preven-• tion of breast cancer: report of the National Surgical Adjuvant Breast and Bowel Project P-1 Study. J Nat/ Cancer Inst 1998, 90: $1371-1388$.

See $\left[46^{* *}\right]$

45. Powles $\mathrm{T}$, Eeles R, Ashley $\mathrm{S}$, et al: Interim analysis of the incidence -• of breast cancer in the Royal Marsden Hospital tamoxifen ranSee $\left[46^{*}\right]$ domised chemoprevention trial. Lancet 1998, 352:98-101.

46. Veronesi $U$, Maisonneuve $\mathrm{P}$, Costa $\mathrm{A}$, et al: Prevention of breast -• cancer with tamoxifen: preliminary findings from the Italian randomised trial among hysterectomised women. Italian Tamoxifen Prevention Study. Lancet 1998, 352:93-97.

These three papers $\left[44^{\circ *}-46^{\circ}\right]$ describe three trials that investigate the role of Tamoxifen as a chemopreventive agent for breast cancer. 
47. Lerman $\mathrm{C}$, Narod S, Schulman $\mathrm{K}$, et al: BRCA1 testing in families with hereditary breast-ovarian cancer. A prospective study of patient decision making and outcomes. JAMA 1996, 275:1885-1892.

48. Evans DGR, Anderson E, Lalloo F, et al: Utilisation of prophylactic mastectomy in 10 European Centres. Dis Markers 1999, 15:148-151.

49. Meijers-Heijboer $\mathrm{H}$, Verhoog L, Brekelmans $\mathrm{C}$, et al: Prophylactic surgery in $B R C A 1 / 2$ mutation carriers: predictive factors and follow-up [abstract]. Am J Hum Genet 1999, 65:111.

50. Hartmann LC, Schaid DJ, Woods JE, et al: Efficacy of bilateral pro- phylactic mastectomy in women with a family history of breast cancer. N Engl J Med 1999, 340:77-84.

This is the most commonly quoted reference to support the suggestion that prophylactic mastectomy reduces risk of breast cancer. The problem is that this study, of necessity, was retrospective and many women did not have genetic analysis performed.

51. Daltrey IR, Eeles RA, Kissin MW: Bilateral prophylactic mastectomy: not just a woman's problem! Breast 1998, 7:236-237.

52. Stefanek M, Enger C, Benkendorf J, Flamm-Honig S, Lerman C: Bilateral prophylactic mastectomy decision making: a vignette study. Prev Med 1999, 29:216-221.

53. Brinton LA, Brown SL: Breast implants and cancer. J Nat/ Cancer Inst 1997, 89:1341-1349.

54. Piver MS, Jishi MF, Tsukada Y, Nava G: Primary peritoneal carcinoma after prophylactic oophorectomy in women with a family history of ovarian carcinoma. A report of the Gilda Radner Familial Ovarian Cancer Registry. Cancer 1993, 71:2751-55.

55. Breast Cancer Linkage Consortium: The pathology of familial breast cancer: differences between breast cancers in carriers of BRCA1 or BRCA2 mutations and sporadic cases. Lancet 1997, 349:1505-1510.

56. Chappuis PO, Rosenblatt J, Foulkes WD: The influence of familial

- and hereditary factors on the prognosis of breast cancer. Ann Oncol 1999, 10:1163-1170.

This reference summarizes the studies investigating survival differences in women who have breast cancer who are BRCA1/BRCA2 carriers versus sporadic cases.

57. Verhoog LC, Brekelmans CT, Seynaeve $C$, et al: Survival and tumour characteristics of breast-cancer patients with germline mutations of BRCA1. Lancet 1998, 351:316-321.

58. Foulkes WD, Wong N, Brunet JS, et al: Germ-line BRCA1 mutation is an adverse prognostic factor in Ashkenazi Jewish women with breast cancer. Clin Cancer Res 1997, 3:2465-2469.

59. Lee JS, Wacholder S, Struewing JP, et al: Survival after breast cancer in Ashkenazi Jewish BRCA1 and BRCA2 mutation carriers. J Natl Cancer Inst 1999, 91:259-263.

60. Verhoog LC, Brekelmans CT, Seynaeve C, et al: Survival in hereditary breast cancer associated with germline mutations of BRCA2. J Clin Oncol 1999, 17:3396-3402.

61. Early Breast Cancer Trialists' Collaborative Group: Systemic treatment of early breast cancer by hormonal, cytotoxic, or immune therapy. 133 randomised trials involving 31,000 recurrences and 24,000 deaths among 75,000 women. Lancet 1992, 339:71-85.

62. Robson M Gilewski T, Haas B, et al: BRCA-associated breast cancer in young women. J Clin Oncol 1998, 16:1642-1649.

63. Cannistra SA: BRCA1 mutations and survival in women with ovarian cancer [letter]. N Engl J Med 1997, 336:1254; discussion $1256-1257$

64. Johannsson O, Ranstam J, Borg A, Olsson H: BRCA1 mutations and survival in women with ovarian cancer. N Engl J Med 1997, 336:1255-1256; discussion 1256-1257.
65. Whitmore SE: BRCA1 mutations and survival in women with ovarian cancer [letter]. N Engl J Med 1997, 336:1254-1255; discussion 1256-1257.

66. Modan B: BRCA1 mutations and survival in women with ovarian cancer [letter]. N Engl J Med 1997, 336:1255; discussion 1256-1257.

67. Pharoah PD, Easton DF, Stockton DL, Gayther S, Ponder BA: Survival in familial, BRCA1-associated, and BRCA2-associated epithelial ovarian cancer. United Kingdom Coordinating Committee for Cancer Research (UKCCCR) Familial Ovarian Cancer Study Group. Cancer Res 1999, 59:868-871.

68. Shen SX, Weaver Z, Xu X, Li C, Weinstein M, Chen L, et al: A targeted disruption of the murine brca1 gene causes gamma-irradiation hypersensitivity and genetic instability. Oncogene 1998, 17: 3115-3124.

69. Sharan SK, Morimatsu M, Albreicht U, et al: Embyronic lethality and radiation hypersensitivity mediated by Rad 51 in mice lacking brca2. Nature 1997, 386:804-810.

70. Coleman $\mathrm{CN}$ : Molecular biology in radiation oncology. Radiation oncology perspective of BRCA1 and BRCA2. Acta Oncol 1999, 38 (Suppl 13):55-59.

71. Early Breast Cancer Trialists' Collaborative Group: Ovarian oblation in early breast cancer: overview of the randomised trials. Lancet 1996, 348:1189-1196.

72. Frank TS, Manley SA, Olopade OI, et al: Sequence analysis of BRCA1 and BRCA2: correlation of mutations with family history and ovarian cancer risk. J Clin Oncol 1998, 16:2417-2425.

Affiliation: Section of Cancer Gentics, Institute of Cancer Research and Royal Marsden NHS Trust, Sutton, Surrey, UK

Correspondence: Rosalind A Eeles MA, MRCP, FRCR, PhD, Clinica Senior Lecturer and Honorary Consultant in Cancer Genetics and Clinical Oncology, Institute of Cancer Research and Royal Marsden NHS Trust, Downs Road, Sutton, Surrey SM2 5PT, UK. Tel: +44 (0)208661 3642; fax: +44 (0)208 7701489 ; e-mail: ros@icr.ac.uk 